\title{
Memória e hipertexto: uma reflexão sobre o conhecimento relacional
}

\author{
Memory and hypertext: a reflection \\ on relational knowledge
}

Giulia CRIPPA'

Glória Carolina BISOFFI2

\section{RES U M O}

Este artigo analisa as mudanças que as formas de organizar a memória sofreram desde a Antiguidade até se transformarem nos atuais sistemas artificiais de memória. Objetiva traçar um paralelo entre a arte da memória, que associa imagens a textos específicos, e o hipertexto, que também utiliza associações, mas de forma não linear. Emprega o método exploratório com abordagem qualitativa, envolvendo a coleta de textos sobre arte da memória e hipertexto, que permitem resgatar aspectos histórico-culturais que trouxeram modificações na forma e no uso da arte da memória e possibilitaram a criação do hipertexto. Estuda, ainda, semelhanças entre os sistemas artificiais de memória, criados por diferentes culturas para que o conhecimento produzido pela sociedade não se perdesse.

Palavras-chave: Conhecimento. Hipertexto. Memória.

\section{A B S T R A C T}

This paper analyzes the changes the ways of organizing memory have undergone since ancient times, turning them into the current artificial memory systems. It aims to draw a parallel between the art of memory (which associates images to specific texts) and the hypertext (which also uses associations, but in a non-linear way). Our methodology consisted of a qualitative approach, involving the collection of texts about the art of memory and hypertext; this enables us to salvage the historical-cultural changes which have modified form and use of the art of memory and allowed the creation of hypertext. It also analyzes the similarities among artificial memory systems created by different cultures in order to prevent loss of knowledge produced by society.

Keywords: Knowledge. Hypertext. Memory.

\section{N T RO D U ÇÃ O}

Neste artigo será apresentada a maneira como diferentes culturas desenvolveram técnicas para impedir que o conhecimento produzido na sociedade se perdesse. Essa era uma das funções da arte da memória

\footnotetext{
1 Professora Doutora, Universidade de São Paulo, Faculdade de Filosofia, Ciências e Letras de Ribeirão Preto, Curso de Ciência da Informação e da Documentação. Av. dos Bandeirantes, 3900, Monte Alegre, 14040-901, Ribeirão Preto, SP, Brasil. Correspondência para/Correspondence to: G. CRIPPA.E-mail: < giuliac@ffclrp.usp.br>.

2 Bibliotecária. Ribeirão Preto, SP, Brasil.

Recebido em 25/11/2010 e aceito para publicação em 3/2/201 1 .
} 
a atual Internet (que pode ser considerada um grande hipertexto). Também na ficção pode ser reconhecido o uso da arte da memória associado à função de hipertexto. "A misteriosa chama da rainha Loana" (Eco, 2005) e "O nome da Rosa", de Umberto Eco (Eco, 2009), narram situações em que elementos visuais são associados a conteúdos e os conteúdos referentes a cada imagem se intercomunicam.

"A misteriosa chama da rainha Loana" (Eco, 2005) conta como o personagem Giambattista Bodoni, que perdeu a memória biográfica, tenta relembrar de fatos de sua história pessoal a partir de materiais variados localizados em diferentes cômodos da casa onde viveu com seus pais. Havia selos, livros de aventura, gibis, jornais, discos, revistas e seus próprios cadernos de escola. Inicialmente, foi preciso reunir esse material, uma vez que estavam espalhados em diversos cômodos da casa; após uma seleção, o que mais interessava foi organizado no escritório que pertenceu ao avô do personagem.

A casa é um local desconhecido para o personagem e pode ser comparada a um labirinto, e os materiais encontrados podem ser comparados aos disponíveis na Internet (que precisam ser selecionados e organizados pelo leitor de forma que façam sentido para sua pesquisa). Com referência aos teoremas para movimentação dentro de um labirinto (Rosenstieh citado por Leão, 2005, p.99) - que serão abordados na seção 2 -, Giambatista move-se como explorador pelas partes da casa que atualmente desconhece, como se estivesse desenrolando o fio de Ariadne. Após a fase de identificação do ambiente e reunião dos diversos itens, começa a selecionar o que será analisado e os organiza no escritório do avô (nessa fase, enrola o fio para reconstruir seus passos e avaliar quanto pode avançar no percurso).

Apesar de ser inicialmente estranha ao personagem, a casa se constitui um lugar de memória, já que em cada cômodo o personagem entra em contato com as imagens (em diversos suportes) que despertam, pouco a pouco, sua memória (como proposto pela arte da memória, as coisas estão dispostas em lugares e cada imagem corresponde a um conteúdo significativo).

Em "O nome da Rosa" (Eco, 2009) existe uma biblioteca medieval em forma de labirinto que reproduz o mapa do mundo da época em que foi criada. É composta por cinquenta e seis salas, sendo quatro heptagonais e cinquenta e duas quadradas ou ligeira- mente trapezoidais, e, dessas, quatro são sem janelas, vinte e oito abertas para fora e dezesseis para dentro, distribuídas em quatro torreões, com cinco salas de quatro lados e uma de sete, cada torreão representando um ponto cardeal. Dentro de cada sala há armários numerados contendo livros. Sobre o arco de cada sala há um cartaz com um versículo do Apocalipse de São João; alguns cartazes eram pretos, outros, vermelhos; destacando-se a primeira letra de cada versículo em vermelho chegava-se aos nomes dos lugares de origem das obras, dos autores ou de onde os bibliotecários achavam que deveria ser a correta proveniência do autor (evidencia-se uma tentativa de correção de erros da natureza). Sabendo disso, e tendo como referência o mapa do mundo, o bibliotecário encontra as obras das quais necessita segundo a seguinte disposição: Norte, Anglia e Germani; Oeste, Galia e Hibernia; Sul, Roma, Yspania, Leones e Aegyptus; Leste, ludaea e Fons Adae; entre Leste e Norte, Acaia. Trata-se de um exemplo de "memória para coisas" no qual, para se encontrar as obras no labirinto, é preciso ter como referência a imagem do mapa do mundo e associar a cada região (Norte, Oeste, Sul, Leste) palavras que remetem à classificação das obras segundo o lugar onde foram escritas.

Os personagens Guilherme e Adso sabem que a causa dos assassinatos que tentam esclarecer está dentro da biblioteca. Por ela ser um labirinto, na primeira vez em que a visitaram, seguiram o teorema da Ariadne Louca; na segunda vez, o teorema da Ariadne Sábia. Na primeira vez, fizeram uma exploração do espaço da biblioteca e perderam-se, porque não conheciam a forma de caminhar por ela. Na segunda visita, marcaram os caminhos por onde passaram em um mapa que construíram observando o edifício por fora, anotando os versículos em vermelho e destacando a primeira letra de cada frase (que remetia aos conteúdos conforme explicado acima). As palavras formadas a partir da união das primeiras letras de cada frase podem ser comparadas aos links da Internet: da mesma forma que elas remetem aos conteúdos das salas que sinalizam, os links clicados abrem textos relacionados a eles. Como os personagens destas obras, os leitores da Internet também podem se perder ou se encontrar, como em um labirinto, utilizando as mesmas estratégias de pesquisa.

É interessante notar que em ambas as obras a recuperação da informação ocorre por meio de sistemas que funcionam por associação de ideias, semelhantes 
ao cérebro humano; as informações não estão hierarquizadas em categorias - esse raciocínio será importante ao longo deste estudo para demonstrar as mudanças ocorridas nas formas de armazenamento e recuperação da informação.

\section{A ARTE DA MEMÓRIA}

\section{Antiguidade}

A criação da arte da memória é atribuída aos gregos, foi transmitida aos romanos e, por meio dos últimos, chegou à tradição europeia. Sua função, na Antiguidade, era o ordenamento dos discursos dos oradores. Cícero conta, em De oratore (Cícero, I séc. a.C) a invenção dessa arte: Simônides (ca. 556-468), famoso poeta grego, foi contratado por Scopas, um nobre de Céos, para compor um poema. No texto, que foi lido em um banquete oferecido por Scopas, o poeta homenageou seu anfitrião e incluiu uma passagem em que louvava os deuses Cástor e Pólux. $\bigcirc$ nobre pagou apenas a metade, alegando que, como o poema também era dedicado aos deuses, a diferença deveria ser cobrada deles. Em seguida, Simônides foi avisado de que dois jovens o aguardavam fora do palácio, mas, ao sair, não encontrou ninguém; quando voltou, o palácio desabara e morreram todos que estavam em seu interior. Dessa forma, Cástor e Pólux pagaram sua parte do poema. Simônides ajudou as famílias dos mortos na identificação dos corpos porque se lembrava dos lugares ocupados por eles e de suas roupas.

Yates (2007) afirma que Simônides foi responsável pelo avanço da mnemônica ao ensinar regras que, embora advindas de uma tradição oral mais antiga, tratavam o tema de forma nova. As invenções atribuídas a ele indicam a emergência de uma sociedade mais complexa, na qual os poetas tinham uma posição definida; nesse contexto de mudança cultural, é comum que uma pessoa eminente seja classificada como inventora.

As informações sobre a arte da memória chegaram aos dias atuais por meio de três obras latinas: Ad Herennium (escrita por um autor anônimo de Roma), De Oratore, de Cícero e Institutio oratória, de Quintiliano (s.d., online). Foram as regras expostas no Ad Herennium que influenciaram a posterior tradição da memória ocidental. Nessa obra, a arte da memória foi descrita como uma escrita interior, que consiste na criação de lugares e imagens.

Quanto à teoria dos lugares, um locus pode ser uma casa, um templo ou outros tipos de construção, desde que seja facilmente fixado pela memória. Pode ser usado várias vezes, como a tábua de cera na qual se escrevia; deve ser associado um signo distintivo a cada cinco loci (por exemplo, pode-se marcar o quinto locus por uma mão de ouro); os loci devem ser desertos e solitários, porque a movimentação de pessoas enfraquece as impressões; os loci não devem ser muito parecidos, já que a semelhança pode confundir; devem ter tamanho moderado; não devem ser excessivamente iluminados ou escuros; os intervalos entre os loci devem ter cerca de nove metros, para que o objeto não fique muito perto ou distante da visão.

Quanto à teoria das imagens, elas são símbolos do que se quer lembrar; há dois tipos de imagens: um para "coisas" (res), relacionado à memoria rerum, cuja finalidade é lembrar a ordem das ideias principais do discurso; e outro para "palavras" (verba), relacionado à memoria verborum, com a finalidade de se lembrar a ordem de cada palavra do discurso. As imagens devem ser impressionantes; em Ad Herennium são mencionadas pessoas "com coroas ou mantos púrpura [...], alguém manchado de sangue, enlameado ou sujo de tinta vermelha $[\ldots]^{\prime \prime}$. A mesma obra exemplifica, ainda, a "memória para coisas", considerando-se o caso de um advogado de defesa no seguinte processo:

A acusação diz que o réu assassinou um homem por envenenamento, apresentou como motivo do crime o recebimento de uma herança e declarou que esse ato teve muitas testemunhas e cúmplices.

Imaginemos o homem em questão deitado na cama, doente, se o conhecemos pessoalmente. Se não o conhecemos, escolheremos alguém para ser nosso doente, mas não um homem de baixo estrato social, de modo que venha à mente de forma imediata. Colocaremos o acusado ao lado da cama, segurando em sua mão direita uma xícara e na esquerda comprimidos e, no dedo anular, testículos de carneiro. Desse modo, teremos na memória o homem envenenado, as testemunhas e a herança (Rhetorica, p.xxii).

A imagem de cada objeto remete a um fato específico do processo: a xícara lembra o envenenamento; os comprimidos, o testamento e a herança; e 
os testículos de carneiro, devido à semelhança verbal com testes, as testemunhas. $\bigcirc$ próprio doente deverá assemelhar-se à vítima ou a alguém conhecido (mas não alguém de classe social inferior, porque, como sugerido no trecho acima, uma pessoa pertencente à camada social mais elevada será mais facilmente lembrada). Segundo Yates (2007), o objetivo do advogado é recordar detalhes ("coisas") do processo, criando na memória um arquivo para seus casos. A imagem mencionada é posicionada como uma etiqueta no primeiro lugar do arquivo da memória, onde estão os registros sobre o envenenamento. Ao buscar algo sobre o caso, o advogado depara-se com a imagem previamente atribuída à "coisa" e ela o remete ao conteúdo completo do processo.

Em relação à "memória para palavras", é exigido um número maior de lugares do que o necessário à memorização das noções de um discurso, e o método para memorização de um verso, por exemplo, não funcionará se ele não for decorado antes que as palavras sejam representadas por imagens e estas alocadas em lugares específicos.

Ad Herennium remete a tratados gregos de retórica já desaparecidos, constituindo-se a principal fonte para estudo da arte da memória clássica (Yates, 2007, p.21). De oratore, de Cícero, cita resumidamente as regras mnemônicas expostas no Ad Herennium (De oratore, II); Quintiliano, em De institutione oratoria, refere-se à arte da memória com reservas sobre sua utilidade, porém mais detalhadamente do que Cícero (De institutione oratória, XI). Ambos os autores presumem que os leitores conheciam a memória artificial à qual se referiam.

O uso da mnemônica está relacionado a duas principais correntes de pensamento que tratavam da memória na Antiguidade: aristotélica, segundo a qual as imagens mentais permitiam a passagem da percepção ao pensamento e, nesse caso, a arte da memória associava intenções abstratas a símbolos físicos, tornando a memória mais eficaz; e platônica, que imputava às imagens a possibilidade de se alcançar as Ideias.

Os teóricos da arte da memória referem-se às seguintes doutrinas aristotélicas (Rossi, 2004): a) tese da presença necessária da imagem ou fantasma, visando ao funcionamento da memória; para Aristóteles, a imaginação é intermediária entre percepção e pensamento, porque as percepções captadas pelos cinco sentidos são trabalhadas pela imaginação, e as imagens (que são como sensações enfraquecidas) resultantes constituem o material da faculdade intelectual; a imagem mental assim formada é comparada, pelo autor, a um retrato pintado, "cuja duração descrevemos como memória"; b) tese de que a lembrança (recuperação voluntária do conhecimento ou da sensação ocorrida entre os conteúdos da memória) seja facilitada pela ordem e pela regularidade, como ocorre com as proposições matemáticas; c) formulação de uma lei da associação segundo a qual as imagens e as ideias se associam em virtude da semelhança, da oposição, ou da contiguidade (De memoria et reminiscentia, IV séc. a.C. ).

Segundo o platonismo, o conhecimento não advém das impressões sensoriais. Platão afirma que existem nas memórias humanas as formas das Ideias, realidades conhecidas pela alma antes de se movimentar para o nível inferior; por isso, o verdadeiro conhecimento resulta da rememoração das Ideias vistas por todas as almas na realidade superior, das quais todos os objetos sensíveis (correspondentes às coisas terrenas) são cópias imperfeitas.

Nas cópias terrenas da justiça e da temperança, e das outras ideias que são preciosas para as almas, não há luz; somente alguns poucos, aproximando as imagens por meio dos obscuros órgãos dos sentidos, contemplam nelas a natureza daquilo que imitam (Platão, 1998, p.35).

Essa diferenciação é importante porque na ldade Média predomina a tendência aristotélica como fundamento filosófico para a utilização da arte da memória - considerada uma técnica para melhor memorização dos dogmas religiosos, das graças alcançadas no Paraíso por quem os seguisse corretamente, e das punições do Inferno reservadas aos pecadores. No Renascimento, essa arte é influenciada pelas teorias platônica, cabalística, lulliana e hermética, que integravam o neoplatonismo, dentro do qual a arte da memória era usada com a finalidade de se alcançar as verdades universais.

\section{Idade Média}

Durante a ldade Média, a arte da memória continuou fundamentada nos princípios clássicos dos lugares e das imagens, havendo uma distinção entre memória natural, que prescinde de treinamento especial, e memória artificial, faculdade que pode ser desenvol- 
vida. Entretanto, a mnemônica passou a ter, principalmente, a função de instrumento de ensino para a Igreja, o que ficou mais evidente com a escolástica - cujas bases filosóficas eram De inventione (conhecida como a "Primeira Retórica" de "Tullius"), Ad Herennium (ou "Segunda Retórica", erroneamente creditada a Cícero, e relacionada a De inventione, realmente escrita por Cícero) e De memoria et reminiscentia (conhecido como um anexo de De anima). A associação entre De inventione e Ad Herennium, ambas atribuídas a Cícero, permite a compreensão da forma medieval da memória artificial, porque na primeira obra são ressaltadas a ética e as virtudes, que são as "invenções" ou "coisas" presentes no discurso do orador; na segunda, são apresentadas as regras de como as "coisas" deveriam ser guardadas na sala do tesouro da memória.

Tomás de Aquino combinou as teorias aristotélica ("especulativa") e ciceroniana ("técnica"), utilizando a psicologia de Aristóteles para justificar filosoficamente o uso da memória artificial, e retomando a definição de Cícero, segundo a qual a memória é uma parte da virtude da Prudência, e propôs quatro regras para aperfeiçoá-la, que perduraram até a introdução da imprensa:

Tullius (e outra autoridade no assunto) diz em sua Retórica que a memória não é aperfeiçoada apenas pela natureza, mas tem muito de arte e fabricação: e há quatro (preceitos) dos quais um homem pode tirar proveito a fim de bem recordar.

I) Primeiro é que deve utilizar alguns traços similares entre as coisas das quais se quer lembrar; esses traços não devem ser muito conhecidos, porque somos mais impressionados por coisas incomuns e a alma fica mais absorvida por elas; é por isso que nos lembramos melhor das coisas vistas na infância. Assim, é necessário inventar similitudes e imagens, pois as intentiones simples e espirituais escapam facilmente à alma, a menos que estejam ligadas a similitudes corporais, pois a cognição humana é mais forte no que diz respeito às sensibilia. Por isso, a (faculdade da) memória é situada na (parte) sensorial da alma.

II) Segundo, é necessário dispor as coisas das quais se quer lembrar em uma ordem determinada, de modo que a partir de um determinado ponto lembrado se possa facilmente atingir o seguinte. Por isso, o Filósofo diz em seu livro De memoria: "Algumas pessoas se lembram a partir de lugares. Assim conseguem passar rapidamente de um ponto a outro ponto'.

III) Terceiro, deve-se demorar com atenção nas coisas das quais se quer lembrar, e se apegar a elas com sentimento; pois o que é fortemente impresso na alma não escapa tão facilmente dela. Por isso, Tullius diz em sua Retórica que a "atenção conserva as figuras completas dos simulacros".

Quarto, é necessário meditar com frequência naquilo que se quer lembrar. Por isso, o Filósofo diz no livro De memoria que "a meditação preserva a memória", porque, como ele diz, "o hábito é como a natureza. Por isso, nos lembramos facilmente das coisas nas quais pensamos com frequência, passando de uma a outra, como se existisse uma ordem natural" (Tomás de Aquino, 1936, p.218).

Dentro desse contexto, a arte da memória medieval servia para que se lembrassem lugares como Inferno e Paraíso. Yates (2007) afirma que o Inferno de Dante é um sistema de memória que objetiva a memorização de cada parte do Inferno e as punições relacionadas a esses lugares.

A tradição da memória passou por mais uma mudança com o advento da imprensa. Embora tenha perdido sua função, a arte da memória sofreu a influência do neoplatonismo, principal movimento filosófico do Renascimento, transformando-se em uma arte hermética. Para a compreensão dessa transição é necessário conhecer a cabala e a arte de Ramón Lull.

A Cabala (qabbalah, "tradição") ficou conhecida na Europa após a expulsão dos sefarditas da Espanha e devido à divulgação das obras de Lull; participa do comentário à Torá (correspondente aos livros do Pentateuco - Velho Testamento), juntamente com a tradição interpretativa rabínica representada pelo Talmud, e consiste de uma técnica de leitura e representação do texto sagrado. Uma das versões da tradição cabalística, a Cabala teosófica, que trata das Sefirot, é comparável às teorias das correntes cósmicas que surgem também nas tradições hermética, gnóstica e neoplatônica. As dez Sefirot são consideradas as dez hipóstases da divindade no processo de emanação, são entidades intermediárias entre Deus e o mundo, ou aspectos interiores da própria divindade, representando a diversidade das formas em que Deus se expande para formar a multiplicidade do universo, e constituindo outros 
canais ou degraus que conduzem a alma de volta para Deus. Por isso, o texto da Torá é tratado pelo cabalista como um aparato simbólico que se relaciona às realidades místicas e metafísicas, e cuja leitura deve revelar quatro sentidos (literal, alegórico-filosófico, hermenêutico e místico).

Existem três técnicas fundamentais de leitura:

- Notariqon: é a técnica do acróstico (as iniciais de uma série de palavras formam outra palavra), que busca combinações significativas para codificação e decodificação de um texto;

- Gematrya: consiste na formação de palavras com sentido diferente, mas com o mesmo valor numérico, para a investigação das analogias entre as coisas ou ideias designadas (em hebraico os números são representados por letras do alfabeto); cada palavra tem, portanto, um valor numérico que deriva da soma dos números representados por cada letra). Por exemplo, soma dos valores de $\mathrm{YHVH}$ resulta em 72, o que leva à procura dos 72 nomes de Deus;

- Temurah: corresponde à técnica do anagrama; trata-se do procedimento por meio do qual Deus criou o mundo e, segundo o Sefer Yetsirah, ou Livro da Criação, escrito entre os séculos II e IV, os materiais e as pedras, ou os 32 caminhos da sabedoria com que lahvè criou o mundo, são as 10 Sefirot e as 22 letras do alfabeto (Eco, 2001).

Ramón Lull nasceu em Mallorca entre 1232 e 1235, e morreu em 1316; contemporâneo de Tomás de Aquino, criou uma arte com fundamento nas três religiões existentes na Península lbérica em sua época.

Para Yates (2007) havia um elemento cabalista no lullismo, uma vez que a meditação por meio de combinações de letras era uma prática desenvolvida particularmente na cabala espanhola. Lull não utilizou as letras hebraicas em sua Ars Magna, mas adaptou a cabala a seus objetivos, fazendo uso de um alfabeto de nove letras (b, $c, d, e, f, g, h, i, k)$, às quais fazia corresponder, em uma tabula generalis, uma lista de seis conjuntos de nove entidades que representam os conteúdos atribuíveis, em ordem, às nove letras. Há, portanto: nove Princípios Absolutos (ou Dignidades Divinas, que podem ser identificadas às Sefirot cabalísticas) a partir dos quais as Dignidades comunicam sua natureza e se espalham na criação; nove Princípios Relativos; nove tipos de Questões; nove Sujeitos; nove Virtudes; nove Vícios (Eco, 2001). Além do alfabeto, foram criadas figuras com a função de associar as letras, originando todas as combinações possíveis, que correspondiam, por sua vez, a um conjunto de proposições verdadeiras. As figuras eram móveis e formavam círculos que giravam graças a rodas e, assim, chegava-se às combinações dos conceitos. Como se obtinham 1680 combinações, as proposições que contrariassem os dogmas cristãos deveriam ser desconsideradas, já que, segundo Eco (2001), essa arte é um instrumento para que sejam relembradas as formas de argumentação válidas favoráveis a uma tese pré-existente.

Nos textos de Lull (e nos escritos neles baseados), a criação de uma lógica entendida como chave da realidade universal e referente às articulações do mundo real une-se à aspiração para um ordenamento de todas as ciências e de todas as noções que correspondam ao próprio ordenamento do cosmos (Rossi, 2004). O aprendizado das regras da arte e a classificação ordenada das noções pressupõem a construção de um sistema mnemônico.

\section{O Renascimento e o teatro de Giulio Camillo}

As obras fundamentais para os magos renascentistas foram escritas entre os séculos II e III d.C., mas não se tratava da sabedoria egípcia: baseavam-se na essência pagã do cristianismo, religião com influências mágicas e orientais (Yates, 1964).

Tot, escriba dos deuses e divindade da sabedoria na cultura egípcia, era identificado pelos gregos com Hermes, ao qual chamavam Três Vezes Grande (Trimegisto). Essa entidade era aceita pela Renascença como uma pessoa real, autor dos textos herméticos. Lactâncio (240 d.C. - 320 d.C.) afirma que Hermes "atestava a majestade do supremo e único Deus mencionando-O pelos mesmos nomes que Lhe damos - Deus Pai". "Pai" é empregado frequentemente para designar o ente supremo nos textos herméticos. Ainda é atribuído a Hermes o uso da expressão "Filho de Deus", conforme a seguir:

"Hermes, no livro entitulado A palavra perfeita, utilizou estas palavras: 'O Senhor e Criador de todas as coisas, a quem nos pareceu certo chamar Deus, por ter Ele feito visível e sensível o segundo Deus... Dado que, portanto, Ele o fez primeiro, só, um e único, pareceu-Lhe belo e bem provido de tudo quanto é bom; e Ele 
santificou-O e $\mathrm{O}$ amou totalmente, como a Seu próprio Filho'" (Lactâncio citado por Yates, 1964, p.19).

A palavra perfeita ou Sermo perfectus é a tradução correta do título do original grego do Asclépio, que contém a descrição da fabricação de ídolos pelos egípcios, e que se santificou por conter a profecia referente ao Filho de Deus (Yates, 1964).

Embora existam outros exemplos, este trabalho ficará restrito à explicação do teatro da memória de Giulio Camillo, um dos casos mais representativos da adaptação da arte da memória ao Renascimento, uma vez que o objetivo é demonstrar que tanto a referida arte como o hipertexto criam relações entre textos por meio de elementos visuais: imagens e links, respectivamente.

Giulio Camillo Delminio (1480-1544) alcançou grande popularidade graças à divulgação, na Europa, das teorias cabalística, lulliana e hermética, as quais convergem em sua obra; foi representante do Renascimento veneziano e sua pretensão era construir uma memória artificial baseada na verdade:

\begin{abstract}
Ora, se os oradores da Antiguidade, em seu desejo de situar dia a dia as partes do discurso a ser pronunciado, as confiavam a lugares tão frágeis quanto as próprias coisas, é justo que nós, em nosso desejo de guardarmos para sempre a natureza eterna de todas as coisas que podem ser expressas pelo discurso [...] queiramos atribuir-lhes lugares eternos (Almeida, 2005, p.225)
\end{abstract}

Concebeu um teatro ideal, chamado de a memória, cuja função era resgatar do esquecimento determinados conceitos, com fundamento nos princípios clássicos da arte da memória. Para construí-lo, Camillo adaptou a seu projeto mnemônico o teatro vitruviano, cujo fundo do palco possuía cinco portas decoradas, usadas pelos atores para entrar em cena e sair. $\bigcirc$ teatro camilliano era construído em madeira, estruturado circularmente (como o romano), constituído por quarenta e nove lugares: sete degraus separados por corredores de acesso em sete áreas que representam as colunas da sabedoria da casa de Salomão. Em cada degrau há portões ou portas imaginários decorados por imagens (correspondentes aos lugares de memória), o que inviabilizava a existência de público. Um espectador que ocupasse o lugar onde existiria um palco veria diante de si as imagens, sob as quais havia várias caixas, contendo materiais a cujos temas as imagens referiam. Na Antiguidade, as pessoas pertencentes às classes sociais mais elevadas ocupavam os lugares mais baixos, por isso Camillo faz corresponder ao primeiro degrau de seu teatro sete medidas essenciais (sete planetas) das quais dependem as outras.

A estrutura do teatro remete à ordem do Universo por meio da relação entre suas partes: Deus é criador do Universo (que também é parte de Deus). O Universo é dividido em quatro hierarquias descendentes: a) mente cósmica (mundo sobreceleste); b) alma cósmica (mundo celeste); c) reino da natureza (mundo sublunar); d) reino da matéria, que apoia o mundo sublunar.

O grau mais baixo do teatro representa os mundos sobreceleste e celeste, onde os sete planetas (cujas imagens são mais bem retidas pela memória) são relacionados, respectivamente, às Sefirot e aos anjos, da seguinte forma: Lua-Malkut-Gabriel, Mercúrio-lessod-Miguel, Vênus-Hod/Netsach-Honiel, Sol-Tiferet-Rafael, Marte-Guevurá-Camael, Júpiter-Hessed-Zadchiel, Saturno-Biná, Zaphchiel. Sefirot e anjos correspondem ao mundo sobreceleste; os planetas representam o mundo celeste. $\bigcirc$ mundo sublunar está representado do segundo ao sexto graus, que são marcados por símbolos emanados pelas Sefirot. $O$ símbolo do segundo grau é o Banquete, oferecido por Oceano aos deuses. Da união entre as águas da sabedoria (Oceano) e os deuses (Ideias divinas) nascem os elementos mais simples, no primeiro dia da Criação. No terceiro grau está Caverna das ninfas, que teciam enquanto abelhas entravam e saíam para produzir mel, numa representação da formação dos elementata ou coisas criadas, em estágio avançado da Criação (Camillo utiliza o comentário cabalístico sobre o Gênese para compor esta passagem). O quarto grau representa o surgimento da humanidade, sob as imagens das três Górgonas (que possuíam somente um olho) - em referência à tríplice alma humana cabalística, descrita no Zohar: Nessamah, superior, Ruach, intermediária e Nefele, inferior. A alma humana une-se ao corpo no quinto grau, onde estão Pasifaé e o Touro. Pasifaé apaixona-se pelo Touro, representando o desejo da alma humana pelo corpo. As Sandálias de Mercúrio do sexto grau remetem às atividades realizadas pelo homem sem artifícios. $\bigcirc$ sétimo grau, por sua vez, representado por Prometeu, está relacionado às ciências, às artes, à religião e à lei. 
Conforme já mencionado, a partir da invenção da imprensa e com a difusão dos textos impressos no Renascimento, a arte da memória perdeu sua função original: a memorização de textos; a memória, antes armazenada em um suporte interno, o cérebro humano, passou a ser confiada aos suportes externos, os livros impressos. A maior produção de livros ocasionou a primeira revolução no acesso à informação, uma vez que, havendo maior circulação de livros, mais pessoas tinham acesso a seus conteúdos; e fez com que aumentassem os repertórios das bibliotecas com mais velocidade: passou-se a elaborar as técnicas para a construção das bibliografias e iniciou-se a catalogação normalizada (Moreiro González, 1998).

Para armazenar e recuperar as informações, as bibliotecas sempre criaram sistemas de memória artificial, de acordo com suas necessidades: na ficção, um dos exemplos é a biblioteca labiríntica descrita em "O nome da Rosa", cujo funcionamento, já explicado, remete à arte da memória. Com o aumento de publicações disponíveis a partir do Renascimento, o aprimoramento desses sistemas torna-se importante para que o conhecimento criado não seja perdido.

No século XIX, houve mais um incremento na produção de publicações, decorrente do desenvolvimento científico. Consequentemente, no século XX, foram desenvolvidos dois sistemas de memória artificial para armazenamento e recuperação de informação em bibliotecas, utilizados até hoje, e que se tornaram referência para a organização de bibliotecas: a Classificação Decimal Universal (CDU), criada por Paul Otlet (1868-1944) e Henri la Fontaine (1854-1943), e a Classificação Decimal de Dewey (CDD), criada por Melvil Dewey (1851-1931). Ambos os sistemas funcionam por meio da atribuição de números a categorias nas quais os conteúdos são inseridos.

A CDD categoriza os assuntos em dez classes principais utilizando o sistema decimal, constituindo-se um sistema numérico e hierárquico. Cada uma das dez classes principais é subdividida em dez, e cada uma dessas dez divisões tem dez seções. Então, o sistema tem dez classes principais, cem divisões e mil seções. São combinados elementos de diferentes partes da estrutura para a formação do número que representa o assunto das obras (combinam-se dois elementos de assuntos juntando números que representam áreas geográficas ou épocas) e sua forma. As obras são classificadas por assunto, com extensões para relações entre assuntos, local, época ou tipo do material, produzindo números de classificação de no mínimo três dígitos, mas de tamanho máximo indeterminado, com um ponto decimal antes do quarto dígito, quando houver (por exemplo: 330 para economia +94 para Europa $=$ 330.94 Economia europeia; 973 para Estados Unidos + 005 que é a divisão para periódicos resulta em 973.005 para designar periódicos sobre os Estados Unidos de forma geral). Números que indicam classes devem ser ordenados como números, ou seja: 050, $220,330.973,331$ etc. Letras devem ser ordenadas antes de dígitos quando ocupam a mesma posição, portanto "330.94 A" vem antes de 330.943.

A Classificação Decimal Universal também utiliza o sistema decimal, mas inclui sinais auxiliares para indicar aspectos especiais de um assunto ou relações entre assuntos. Cada número representa uma fração decimal com o ponto decimal inicial omitido, o que determina a ordem de preenchimento. Os identificadores da CDU são pontuados a cada três dígitos: após 61, "Ciências médicas", seguem-se as subdivisões, 611 a 619;611, "Anatomia", subdivide-se de 611.1 a 611.9;611.1 subdivide-se antes de 611 1.2, e assim por diante. Depois de 619 vem 620, passível das mesmas subdivisões.

Os documentos são classificados de acordo com uma combinação de diferentes categorias por meio do uso de símbolos adicionais (Quadro 1).

Em ambos os sistemas, a recuperação da informação ocorre de forma a remeter à arte da memória: a cada obra é atribuído um número (não mais uma

Quadro 1. Símbolos adicionais da Classificação Decimal Universal.

\begin{tabular}{lll}
\hline+ adição & Exemplo: 59+636 Zoologia e criação seletiva de animais \\
$/$ extensão & Exemplo: 592/599 Zoologia sistemática (tudo de 592 a 599 inclusive) \\
$: \quad$ relação & Exemplo: 17:7 Relação entre ética e artes \\
{[] sub-agrupamento algébrico } & Exemplo: $31:[622+669](485)$ Estatísticas de mineração e metalurgia na Suécia (o auxiliar considera 622 + 669 \\
& como uma unidade) \\
$=$ linguagem & Exemplo: $=20$ em Inglês; 59=20 Zoologia, em inglês \\
\hline
\end{tabular}


imagem) que representa o conteúdo a ser recuperado. Entretanto, não se trabalha com associações de ideias (como no Teatro de Giulio Camillo), mas com a classificação hierárquica dos assuntos, tendo como base o sistema decimal. Embora ainda utilizadas, essas formas de organização e recuperação do conhecimento são questionadas desde a década de 1940, quando Vannevar Bush, que propôs o Memex - máquina que funcionaria criando associação entre dois textos -, pensava em uma forma de armazenamento e de recuperação de informação que substituísse as classificações hierárquicas, conforme abordado a seguir.

\section{H I P E R T EXTO}

\section{Histórico}

A ideia do hipertexto estava implícita no Teatro de Giulio Camillo, uma vez que por meio de elementos visuais estáticos, as imagens, o leitor era remetido a diferentes textos: cada imagem era relacionada a um texto. $\bigcirc$ atual hipertexto também relaciona textos por meio de elementos visuais, os links, mas de forma dinâmica: enquanto no Teatro cada imagem era associada a um texto específico, no hipertexto o mesmo link pode levar a vários fragmentos de textos diferentes.

Vagnoni (1997) compara a ideia presente no teatro camilliano e o atual conceito de memória artificial da informática, este último mantendo a pretensão de criar uma memória que, por meio de leis e de uma organização sistemática, possa englobar e disponibilizar, em forma de imagens, as coisas e as palavras que constituem o conhecimento humano. Bologna (1997) também pensa nas semelhanças possíveis entre ambos os sistemas, questionando sobre a forma que assumiria o teatro se tivesse à sua disposição um computador capaz de conectar os nós das redes conceituais identificadas. Possivelmente, assumiria-se a forma do hipertexto idealizado no século XX, já que ambos têm em comum a recuperação dos conteúdos das obras por meio da associação de ideias.

No século XX, pesquisadores como Vannevar Bush, Douglas Engelbart e Theodor Nelson desenvolveram projetos relevantes cujo objetivo era encontrar uma forma de relacionar informação e movimentar-se entre documentos com mais facilidade - projetos que deram origem ao atual hipertexto.
Vannevar Bush (1890-1974) concebeu uma máquina chamada Memex (MeMory Extension), cujo projeto foi publicado na revista Atlantic Monthly, descrito no artigo entitulado "As we may think", em 1945. A máquina consistia de uma mesa de trabalho dotada de várias telas inclinadas nas quais o material poderia ser projetado para leitura, um teclado e um conjunto de botões e alavancas. Os materiais (livros, fotografias, jornais e revistas) seriam introduzidos na máquina por meio das tecnologias do microfilme e da fotografia, e acessados por meio de códigos mnemônicos de classificação. As alavancas permitiriam que os textos fossem consultados página por página, ou de dez em dez páginas, do início ao fim, ou em sentido contrário. Um botão especial conduziria o usuário ao índice do material consultado. Ainda seria facultado ao usuário inserir suas próprias anotações na máquina. A principal função do Memex seria sua capacidade de associar dois elementos diferentes, permitindo ao usuário, assim, criar trajetos de leitura personalizados (Bush, 1945, online).

Nesse mesmo artigo, o ator ressaltou que informações geradas poderiam ser perdidas devido à artificialidade dos sistemas de indexação, que funcionavam segundo regras complicadas e que não correspondiam ao funcionamento do cérebro humano, que trabalha com associações. Por isso pensou em uma máquina que permitiria ao usuário fazer associações de ideias, relacionando diferentes fragmentos de textos. Os percursos criados graças ao Memex, diferentemente dos trajetos mentais, poderiam ser gravados e reproduzidos ao longo do tempo (Vianello Osti, 2004).

Landow (2000) afirma que o texto produzido a partir do Memex exigiria, primeiramente, uma reconfiguração dos fundamentos da prática da leitura e da escrita, unindo essas duas atividades mais do que é possível com a tecnologia do livro. Em segundo lugar, embora Bush, que concebeu o Memex antes do advento da informática, intuía que era necessário algum tipo de textualidade virtual para as mudanças desejadas. Em terceiro lugar, a reconfiguração do texto introduz três novos elementos: indexação associativa (links), percursos entre os links (trail) e conjunto/rede de caminhos (Web), que produzem um texto mais flexível e adaptado - ou até vulnerável - às demandas dos usuários.

Douglas Engelbart desenvolveu o projeto oNLineSystem (NSL) quando era diretor do Augumentation Center Research (ARC), de Stanford. Esse projeto era 
fundamentado nas proposições de Bush, e estudaram-se, pela primeira vez: a) a tela com múltiplas janelas de trabalho; b) a possibilidade de manipular, por meio de um mouse, complexos informacionais representados na tela por símbolos gráficos; c) as conexões associativas (hipertextuais) em bancos de dados ou entre documentos escritos por autores diferentes; d) os grafos dinâmicos para representar estruturas conceituais; e) os sistemas de ajuda ao usuário integrados aos programas (Lévy, 2004). Tratava-se de um experimento cujo objetivo era suprir todas as necessidades de um trabalho de pesquisa científica. Primeiramente, armazenou-se no sistema todo o material a ser disponibilizado aos usuários (especificações, planos, programas, documentos, relatórios, referências bibliográficas, notas etc.). Na fase posterior, foi permitido aos usuários criar documentos eletrônicos baseados na associação de documentos, construir hierarquias de informação e colaborar com outros usuários no desenvolvimento da documentação (Caridad; Moscoso, 1991).

Baseados nas pesquisas de Engelbart, os aprimoramentos que levaram à construção do computador pessoal pela Apple tornaram a informática mais "amigável": o surgimento do Macintosh, em 1984, permitiu a divulgação do hipertexto, já que integrava a comunicação, a edição e o audiovisual, além de introduzir o mouse e o uso dos ícones (Lévy, 2004).

A Theodor Nelson é atribuída a invenção, em 1967, do termo hipertexto, baseando-se no termo espaço hiperbólico, empregado para descrever uma geometria de muitas dimensões. Nelson reconhecia semelhanças entre o texto multidimensional e o espaço hiperbólico, ressaltando a necessidade de que os sistemas textuais refletissem o hiperespaço dos conceitos implícitos no texto, para que permitissem uma leitura mais de acordo com os processos mentais humanos, que têm como modelo espaços multidimensionais (Vianello Osti, 2004). Dessa forma, as máquinas pensadas por Nelson tinham a função de recordar - termo que se refere ao mecanismo da memória que configura grandes problemas de relações analógicas, que não se baseiam na subordinação (não são de natureza hierárquica), mas na associação de ideias. Nelson chamou seu projeto de Xanadu, em referência ao "lugar mágico da memória", citado no poema Kubla Khan, de Samuel Taylor Coleridge. Seu objetivo era armazenar toda a documentação mundial em uma rede que utilizaria o hipertexto para recuperação da informação. Por meio de links e mecanismos disponíveis no próprio sistema, os usuários poderiam recuperar, a partir de seus computadores pessoais, as peças informativas que lhes interessassem, assim como inserir documentos que integrariam a mesma rede. A partir dessa interação entre os usuários e o sistema se forma o docuverse (docuverso), um universo de informações global e horizontal, contendo textos que se relacionariam graças a links que permitiriam navegar entre os documentos e tornariam explícitas as relações semânticas que existiriam entre eles. Acrescentando links novos, os usuários estariam contribuindo para a manutenção da rede que constitui a cultura (Nelson, 1981).

\section{Internet, WWW e hipertexto}

A Internet é um conjunto de redes de computadores interligadas. Seu início remete à Advanced Research Projects Agency Network (ARPANET), que se originou a partir de uma experiência realizada em 1969 pelo governo norte-americano, na área de redes por comutação de pacotes. A Department of Defense Advanced Research Project Agency (DARPA) era responsável por essas pesquisas e, por intermédio da ARPANET, interligava remotamente centros de processamento de dados, somente dentro dos Estados Unidos, com o objetivo de compartilhar recursos de informática, como espaço em disco e bases de dados e programas. $O$ resultado mais importante dessas pesquisas foi o desenvolvimento de um conjunto de códigos de comunicação que permitia a comunicação entre os usuários - o sistema de envio de mensagens dividia a informação em pacotes de tamanhos iguais, que o sistema receptor unia novamente. Apenas empreiteiras norte-americanas atuantes nas áreas militar e de defesa e as universidades que conduziam pesquisas de caráter militar acessavam a ARPANET.

As pesquisas prosseguiram e, em 1988, foi criada a National Science Foundation Network (NSFNET), que substituiu a ARPANET como rede de pesquisa, a última desativada em 1990. A NSFNET era responsável por conectar pesquisadores dos EUA com 12 centros dotados de supercomputadores. A conexão com a NSFNET se fazia por intermédio de centros regionais, cada um oferecendo suporte a uma rede regional. Assim, não somente foi possível a conexão com um centro onde havia um supercomputador, mas também a conexão de todos os centros regionais. Portanto, a Internet (que 
resultou de todos os processos de aperfeiçoamento da ARPANET) surgiu como uma rede cooperativa de computadores sem um órgão central que supervisionasse suas atividades.

Em março de 1989, Berners-Lee e Cailliau (1990) trabalhavam para o Conseil Européen pour la Recherche Nucléaire (CERN), um laboratório de pesquisas europeu sediado na Suiça. Usaram a Internet, - hipertexto e a linguagem Standard Generalized Markup Language (SGML) para confeccionar uma ferramenta, cuja finalidade era difundir rapidamente artigos científicos, publicada com o nome World Wide Web (WWW). Outro artigo, de 1990, descreve o protocolo de transferência por hipertexto Hipertext Markup Language (HTTP, padrão para controlar e permitir uma conexão, comunicação ou transferência de dados entre dois sistemas computacionais), o conceito de browser (ou navegador, software que permite o acesso aos documentos disponibilizados na Internet), o conceito de servidor (software que oferece serviços como e-mail) e a linguagem de marcação de hipertextos (HTML). Baseia-se numa interface gráfica e permite que dados diversos (textos, músicas, sons, animações, filmes, etc.) sejam acessados por um mouse. Para visualizar a informação, utiliza-se um browser que acessa os sites de servidores exibindo-a na tela para o usuário. O usuário pode então seguir os hiperlinks da página para outros documentos ou mesmo enviar informações de volta para o servidor para interagir com ele.

\section{Conceitos e características}

Nelson (1992) conceitua hipertexto como "uma forma de escrita não sequencial - um texto que se espalha em ramificações e permite ao leitor escolher caminhos, [e que deve ser] preferencialmente lido em tela interativa". Bellei (2002) argumenta que essa definição é insuficiente, pois caracteriza o hipertexto a partir de preconceitos relacionados ao texto impresso, sugerindo que ele é linear e sequencial, enquanto o hipertexto é multilinear; que o leitor do texto impresso segue a rota estabelecida pelo autor, e o leitor do hipertexto escolhe seus próprios caminhos. Entretanto, o texto impresso não é, necessariamente, linear, já que um leitor pode decidir não ler um livro página por página - pode consultar diretamente o capítulo com as informações que the interessam; e o hipertexto pode ser lido linearmente, como um texto impresso (caso o leitor decida não seguir os links disponíveis). Apesar de apresentar aspectos como ruptura e continuidade em relação ao texto impresso, o hipertexto é também um texto. Por isso, o autor afirma que o hipertexto tende para uma multilinearidade que já existia no texto impresso.

Segundo Landow (2000, p.8):

Hipertexto [...] significa um texto composto por blocos de palavras (ou imagens) conectadas eletronicamente por trajetos múltiplos, cadeias em uma rede aberta (ou livro eletrônico). $\bigcirc$ hipertexto, em outras palavras, é uma tecnologia da informação na qual um novo elemento, o link (conexão, vínculo) desempenha um papel central. Todas as características práticas, culturais e cognitivas desta mídia derivam do fato de que a conexão dos elementos (linking) cria um mundo novo de conexões e de escolhas para o leitor. $O$ hipertexto pode ser mais propriamente definido como uma forma de escrita multisequencial ou multilinear do que não-linear.

Uma terceira conceituação é dada por Lévy (2004), para quem o hipertexto é, tecnicamente, um conjunto de nós ligados por conexões. Os nós podem ser palavras, páginas, imagens, gráficos ou partes de gráficos, sequências sonoras, documentos complexos que podem eles mesmos ser hipertextos. Os itens de informação não são ligados linearmente, mas cada um deles estende suas conexões em estrela, de modo reticular. $\bigcirc$ autor afirma, ainda, que funcionalmente, um hipertexto é um tipo de programa para a organização de conhecimentos ou dados e para a aquisição de informações e comunicação.

Além de hipertexto, também é necessário conceituar os seguintes elementos estruturais: a) nó: "toda parte informativa suscetível de ser associada por meio de um link ou vínculo" (Caridad; Moscoso, 1991, p.42); b) âncora: o link é o elemento que permite a relação entre dois nós, enquanto a âncora é a parte visível do link e aparece destacada no documento para que, ao ser selecionada, ative a relação, acessando outra parte do hipertexto (Vianello Osti, 2004); c) link: elemento que relaciona dois nós.

Existem três tipos de links: direcionais: que conduzem o leitor a um ponto determinado pelo autor do texto; disjuntivos: quando o termo destacado é ativado com um "clique" do mouse, acessando-se um ponto arbitrário do sistema; conjuntivos: que permitem ao leitor acessar uma informação adicional enquanto o leitor permanece na mesma página. 
A partir dos conceitos são apresentadas as características do hipertexto. Landow (2000) afirma que o hipertexto é caracterizado pela possibilidade de ser analisável, infinitamente duplicado, contextualizado e descontextualizado com grande velocidade, e de ser colocado em rede. Ao referir-se à definição de Nelson (acima comentada), observa que o hipertexto denota um texto composto por blocos de textos (definição de Barthes para lexia) e por vínculos eletrônicos (links) que unem esses blocos. Alguns autores denominam as lexias como nós; ambos os termos correspondem às unidades básicas de informação, formadas por diferentes componentes, como textos, imagens, ícones, botões, sons etc.

Seguindo esse raciocínio, o que caracteriza o hipertexto, estruturalmente, não é a sequencia linear de blocos de significados que vai de $\mathrm{A}$ a $\mathrm{E}$, por exemplo (embora o leitor possa ler dessa forma), mas a possibilidade de trajetórias de leitura multilineares, com percursos como A - B - E - D, possíveis graças às linguagens de programação $S G M L$, que permitem que um significado, em um texto escrito no computador, seja "marcado", e cada vez que a marca é ativada pelo mouse, passa-se daquele significado para outro, ou para outros blocos de significados do conjunto de dados disponíveis (no caso, A, B, C, D, E). Nelson (1992) afirma que o hipertexto deve preferencialmente ser lido em um computador e de forma interativa, exatamente porque as marcas produzidas no meio eletrônico não são praticáveis no meio impresso. Considerando-se os blocos de significados do exemplo, o leitor pode interromper a leitura do texto $A$ em uma palavra marcada na terceira linha que, ativada, acessará o documento B. A linearidade de B poderá ser interrompida por palavras marcadas em suas linhas, que, clicadas com o mouse, passarão para C, D e E; assim como as palavras marcadas no texto $E$ podem permitir o retorno ao texto $D$. Trata-se de uma estrutura que tende para o multicentramento: " $\mathrm{A}$ " não se mantém um texto central por muito tempo porque a mudança para " $B$ " o torna um novo centro transitório que pode, por sua vez, deslocar-se temporariamente para " $E$ ", e assim por diante. Consequentemente, a estrutura hipertextual da Internet, em que as conexões (links) se fazem por meio de uma linguagem específica de marcações conhecida como HTML, incentiva uma navegação errática, na qual o leitor pode facilmente perder-se, esquecendo-se das origens da leitura (Bellei, 2002, p.44).
Em se tratando dos diversos percursos que os leitores podem seguir, Leão, que compara a navegação em um hipertexto à exploração de um labirinto, menciona dois teoremas propostos por Rosenstieh (Leão, 2005, p.99):

a) Teorema da Ariadne Louca: 'Vai sempre explorando novos corredores, desenrolando o fio, e numa encruzilhada onde já não possas explorar mais nada, reenrola o fio no teu corredor'.

b) Teorema da Ariadne Sábia: 'Segue o teu caminho, e se chegares a uma encruzilhada já descoberta, ou se já não tiveres nenhum corredor para explorar, então, nestes dois casos e só neles, reenrola o fio no teu corredor'.

Caso optem pelo primeiro teorema, os leitores agirão de maneira exploratória e obterão informações dispersas; se decidirem utilizar o segundo, farão uso de recursos disponibilizados na Internet, como: a) o botão back, que permite a volta a uma página anteriormente visitada; b) palavras destacadas no texto (sublinhadas e com cor diferente) que, ao serem clicadas, acessam outras páginas; se, por meio do botão back, volta-se à página onde um link foi acionado, este aparecerá com a cor púrpura; c) go menu apresenta a lista das páginas já acessadas; d) comando go to campo a ser preenchido com o endereço do site que pretende visitar; e) bookmarks permite a visualização dos locais marcados como de maior interesse (corresponde à lista de favoritos). Os marcadores citados têm a mesma função que o fio de Ariadne dentro de um labirinto, facilitando a visualização do caminho já percorrido e o prosseguimento da pesquisa.

Quanto à digitalização, Clèment (2004) afirma que, se ela separa o texto do objeto-livro, reduzindo-o a uma sequencia de caracteres, o hipertexto o reorganiza de modo a projetar em uma base de dados textuais não estruturada (Internet, por exemplo) uma rede de links passíveis de serem ativados pelo usuário por intermédio dos recursos acima descritos. Novas capacidades de armazenamento modificam o estatuto da nota de pé de página e das referências cruzadas, não sendo mais necessária a procura do texto citado pelo autor em uma edição que se tornou inencontrável: se estiver digitalizada, pode-se ler partes dela ou sua totalidade. Além disso, é possível a consulta de variantes do mesmo texto graças à instantaneidade de exibição dos textos e à abertura de diversas janelas. 


\section{A Web semântica e as ontologias}

A Web semântica é um projeto do World Wide Web Consortium (W3C), que se iniciou em 1994, no Massachussetts Institute of Technology (MIT) para tratar de problemas concernentes à Internet. $\bigcirc$ projeto da Web semântica foi lançado em 2001 por Tim Berners- Lee e seu grupo de trabalho, e representa o amadurecimento da ideia de Berners-Lee, expressa em 1989, de que a construção da Web devia fundamentar-se na interação semântica dos dados; isto aconteceria devido à hipertextualidade: a associação de nós conceituais a nós documentais descreveria o conteúdo do documento (Berners-Lee, 1989).

Esse projeto envolve a construção de ontologias. No contexto filosófico, ontologia (grego: onto - ser - e logia - discurso escrito ou falado) é a disciplina da metafísica que estuda quais categorias de "coisas" existem. Nos estudos da Web e da inteligência artificial, adaptou-se o termo, que passou a designar o arquivo que explicita e descreve formalmente as relações entre termos e conceitos. As ontologias buscam os conceitos, relacionam as informações presentes em uma página com uma estrutura do conhecimento associada. São uma ferramenta desenvolvida a partir do eXtensible Markup Language (XML), uma das linguagens para construção de páginas da Web; as referidas linguagens utilizam metadados ("dados sobre dados") cuja finalidade é descrever os dados que compõem o documento, como serão utilizados, exibidos, e seu significado em um contexto. $\bigcirc$ diferencial do XML é permitir a inclusão de novos comandos de marcação (tags), se necessário, favorecendo uma descrição mais detalhada dos dados e aumentando as possibilidades de associação entre os documentos e seus significados por meio dos metadados descritivos.

objetivo da Web semântica é o estabelecimento de padrões tecnológicos para facilitar a troca de informações entre pessoas, dispositivos e sistemas de informação eletrônicos por meio de uma linguagem comum.

\section{CONSIDERAÇÕES FINAIS}

Neste trabalho foram apresentadas as transformações pelas quais a arte da memória passou desde a Antiguidade até o Renascimento, fase na qual Giulio Camillo elaborou um sistema de memória artificial cujo funcionamento remete aos raciocínios de Bush (1945) e Nelson (1992), que conduziram à criação do hipertexto. Tanto no teatro camilliano quanto no hipertexto, busca-se armazenar e recuperar informação por meio da associação entre documentos.

Oteatro da memória de Giulio Camillo é um sistema de memória artificial com fundamento no neoplatonismo, cujo objetivo é armazenar e recuperar conhecimentos, e no qual cada imagem corresponde a um texto - portanto, as relações são estáticas. A Internet, considerada um grande hipertexto, também utiliza elementos visuais para relacionar textos, os links, mas isto ocorre de forma dinâmica, já que um link pode remeter a mais de um fragmento de texto. Tanto Camillo quanto Bush tinham como objetivo a criação de um sistema que abarcasse todo o conhecimento concebível e que impedisse seu esquecimento/perda sistema esse que Nelson, posteriormente, denominou hipertexto.

Em se tratando da recuperação da informação, e conforme já abordado, Bush propôs o Memex porque questionava a eficácia das classificações hierárquicas (CDD e CDU). Os usuários de bibliotecas cujos acervos são organizados com base em tais classificações encontram-se na mesma situação que os personagens Adso e Guilherme, de "O nome da Rosa", que desconheciam a lógica da organização da biblioteca labiríntica: embora houvesse uma ordem para a localização dos documentos, era necessário despender tempo para interpretá-la. Mesmo assim, a ordem era baseada em associações, como já explicado. Além disso, as classificações CDD e CDU representam os assuntos das obras por números, o que torna a pesquisa mais confusa.

Com a criação da Internet e a posterior implantação da Web, a disponibilização eletrônica de documentos gerou a necessidade do aprimoramento dos recursos existentes para recuperação adequada dos mesmos. Um dos problemas para a recuperação de informação na Internet é que a maioria das páginas tem metadados atribuídos antes de sua exibição, não sendo possível a inclusão de modificações; o projeto da Web semântica tenta mudar esse panorama, pesquisando formas de inserção de metadados descritores nas páginas mesmo após sua exibição. A ferramenta escolhida pelos idealizadores da Web Semântica para a recuperação das informações é a ontologia, e segue o raciocínio inicial de Bush, pois associam termos e conceitos. 
Aliás, foi por meio da associação de documentos que o personagem Giambatista, de "A misteriosa chama da rainha Loana", recuperou sua memória. Como um usuário da Internet, ele transitou por vários documentos e selecionou aqueles concernentes a sua pesquisa. A Web semântica propõe aprimoramentos que facilitarão as buscas para os usuários, de modo que a seleção de documentos seja menos demorada: pretende-se uma melhora dos motores de busca, que recuperarão apenas documentos cujo assunto seja relacionado ao termo ou conjunto de termos pesquisados.

\section{REFERÊNCIAS}

ALMEIDA, M.J. O teatro da memória de Giulio Camillo. Campinas: Unicamp, 2005. p.225.

ARISTÓTELES. De memoria et reminiscentia. 2001. Disponibile: $<$ http://etext.virginia.edu/toc/modeng/public/AriMemo.html>. Accesso: 2 nov. 2009.

BELLEI, S.L.P. O livro, a literatura e o computador. São Paulo: EDUC, 2002. p. 43-44.

BERNERS-LEE, T. Information management: a proposal. 1989. Available from: <http://www.w3.org/History/1989/ proposal.html>. Cited: 2 Nov. 2009.

BERNERS-LEE, T.; CAILLIAU, R. World Wide Web: proposal for a hypertext project. 1990. Available from: <http://www.w3c.org/ Proposal.html>. Cited: 2 Nov. 2009.

BOLOGNA, C. "Virtualità" e "circolo virtuoso" nell'interpretazione del Theatro de Giulio Camillo. In: NORMANDO, V.; MORONI, N. (Ed.). II mondo virtuale di Giulio Camillo. Roma: Universitá la Sapienza, 1997. Disponibile: <http://www.bta.it/riv/rice/1997/ 05/15/a0/testi/testi.htm>. Accesso: 2 nov. 2009.

BUSH, V. As we may think. Atlantic Monthly. 1945. p. 101-108. Avaliable from: <http://www.theatlantic.com/doc/194507/ bush>. Cited: 2 Nov. 2009.

CARIDAD, M.; MOSCOSO, P. Los sistemas de hipertexto e hipermedios: una aplicación en informática documental. Madrid: Fundación Germán Sánchez Ruipérez, 1991 . p. 23-42.

CLÉMENT, J. Do livro ao texto: as implicações intelectuais da edição eletrônica. In: SÜSSEKIND, F.; DIAS, T. (Org.). A historiografia literária e as técnicas de escrita: do manuscrito ao hipertexto. Rio de Janeiro: Edições Casa de Rui Barbosa, 2004 p. 28-35.

ECO, U. A busca da língua perfeita na cultura europeia. Bauru: EDUSC, 2001. p. 26-90.

ECO, U. A misteriosa chama da raina Loana. Rio de Janeiro: Record, 2005.

ECO, U. O nome da Rosa. Rio de Janeiro: Record, 2009.

LANDOW, G.P. L'ipertesto: tecnologie digitali e critica letteraria. Milão: Mondadori, 2000. p. 8-34.
LEÃO, L. O labirinto da hipermídia: arquitetura e navegação no ciberespaço. São Paulo: Fapesp, 2005. p. 99-100.

LÉVY, P. As tecnologias da inteligência: o futuro do pensamento na era da informática. São Paulo: Editora 34, 2004. p. 33-51.

MOREIRO GONZÁLEZ, J.A. Introducción al estudio de la información y la documentación. Medellín: Universidad de Antioquia, 1998. p. 58. (Colección Medios y Mensajes).

NELSON, T.H. Literary machines. Swarthmore: Pa, self-published, 1981.

NELSON, T.H. Opening hypertext: a memoir. In: TUMAN, M.C. (Ed.). Literacy online: the promise (and peril) of reading and writing with computers. London: The University of Pittsburgh Press, 1992.

PLATÃO. Fedro. Lisboa: Edições 70, 1998.

QUINTILIANO, M.F. De institutione oratória. Disponibile: <http:// www.thelatinlibrary.com/quintilian. html>. Accesso: 11 nov. 2009.

RHETORICA ad Herennium. Available from: <http://rhetoric. byu.edu/primary\%20texts/Ad\%20Herennium.htm>. Cited: 11 Nov. 2009.

ROSSI, P. A chave universal: artes da memorização e lógica desde Lúlio até Leibniz. Florianópolis: EDUSC, 2004. p.42-88.

TOMÁS DE AQUINO, S. Suma teológica: da trinidade. São Paulo: Odeon, 1936.

VAGNONI, D. Itinerario de sapienza e conoscenza virtuale nel "Teatro della memoria", di Giulio Camillo. In: NORMANDO, V.; MORONI, N. (Dir.). II mondo virtuale di Giulio Camillo. Roma: Universitá la Sapienza, 1997. Disponibile: <http://www.bta.it/ riv/rice/1997/05/15/a0/testi/testi.htm>. Accesso: 2 nov. 2009.

VIANELLO OSTI, M. El hipertexto entre la utopia y la aplicación: identidad, problemática e tendências de la Web. Gijón: Trea, 2004. p. 73-93.

YATES, F.A. A arte da memória. Campinas: Unicamp, 2007. p.21-236. (Espaços da Memória).

YATES, F.A. Giordano Bruno e a tradição hermética. São Paulo: Cultrix, 1964. p.14-20. 